\title{
The role of stiffness variation in switches and crossings: comparison of vehicle-track interaction models with field measurements
}

\author{
I. Grossoni ${ }^{*}$, L. M. Le Pen², P. Jorge ${ }^{1}$, Y. Bezin ${ }^{1}$, G. V. R. \\ Watson $^{2}$, D. Kostovasilis ${ }^{1}$, W. Powrie ${ }^{2}$ \\ ${ }^{1}$ University of Huddersfield, Huddersfield, UK \\ ${ }^{2}$ University of Southampton, Southampton, UK
}

This article was accepted for Publication by the Journal of Rail and Rapid Transit. This is the authors as submitted version. An online ahead of print version is available:

https://doi.org/10.1177/0954409719892146

A reference for the current (December 2019) online version may be used as follows:

Grossoni, I., Le Pen, L. M., Jorge, P., Bezin, Y., Watson, G. V., Kostovasilis, D. \& Powrie, W. (2019 - online ahead of print) The role of stiffness variation in switches and crossings: Comparison of vehicle-track interaction models with field measurements. Proceedings of the Institution of Mechanical Engineers, Part F: Journal of Rail and Rapid Transit, Vol.0, pp.0954409719892146.

Later the version of record will become the in print version.

A data set fot the article is available through the online repositories of the Universities of Southampton and Huddersfield who jointly authored the paper.

* Corresponding author: University of Huddersfield, Queensgate, Huddersfield, HD1 3DH, West Yorkshire, UK. Email: i.grossoni@hud.ac.uk 


\section{Abstract}

The performance of Switches and Crossings (S\&Cs) compared with plain line is complicated by the presence of movable parts, changing rail geometry and nonuniformities in the composite and/or trackbed stiffness. These features lead to complex vehicle-track interactions and higher maintenance costs. The trackbed stiffness is the least well controlled engineering property. A greater variability in trackbed stiffness leads to higher differential trackbed settlement and associated poorer track quality. At S\&C changes in trackbed stiffness are exacerbated by changing rail properties which also contribute to changes in the overall composite track stiffness. This work focuses on the role of variations in stiffness on S\&C performance. Field measurements of bearer displacement were carried out using geophones at an S\&C equipped with Under Sleeper Pads (USPs). Vehicle-S\&C interaction was modelled using a multi-body system and finite element method. The trackbed stiffness along the whole of the S\&C was inferred using the measurements of track deflections in an iterative back-calculation taking account of changing rail properties. It is shown that not including the variation in trackbed/composite stiffness leads to significant under/overestimates of the wheel-rail contact forces. USPs are shown to reduce absolute maximum loads, but may increase the variation in deflection.

\section{Keywords}

S\&C, switch panel, crossing panel, trackbed stiffness, composite track stiffness, field measurements, geophones, vehicle-track interaction, FE approach, MBS approach, USP.

\section{Introduction}

Switches and Crossings (S\&Cs) allow trains to change path on railway track systems. However, their performance compared with plain line is complicated by the presence of movable parts, discontinuities in the rail geometry, a changing rail bending stiffness and non-uniform trackbed stiffness. These factors contribute to high failure rates [1], maintenance and renewal costs [2].

Track stiffness may be defined in several ways [3]:

- The trackbed stiffness is the load per unit displacement measured on an unclipped sleeper. It quantifies the support provided by the ballast and underlying soils, together with any under sleeper pads.

- The support system stiffness refers to the compliant components below the rail the rail pad, a USP if present and the trackbed.

- The composite track stiffness is quantified as the deflection per unit load at the wheel-rail interface. It depends on the trackbed and railpad stiffness (i.e., the support system stiffness), and the bending stiffness of the rail.

The word "stiffness" is used where these parameters are quantified per sleeper; if they are determined per metre / unit distance along the track the word "stiffness" is replaced by the word "modulus". 
In most circumstances on plain line the bending stiffness of the rail and the stiffness of the railpad are uniform and the primary variable influencing dynamic vehicle-track interaction via the composite stiffness as seen by the vehicle is the trackbed stiffness. However, at S\&C there is a longitudinal variation in bending stiffness from changing rail sections so that the composite track stiffness will also vary with rail properties.

Additionally the presence of long bearers through some parts of an S\&C increases the ballast contact area [4], resulting in an effectively stiffer asymmetric support. Rapid changes in support stiffness can cause significant variations in wheel-rail loads, poorer geometry and differential settlement $[3,5]$. These effects are likely to be most severe at the locations where the wheel-rail contact patch changes between the rails (the switch tips and the crossing nose), where additional dynamic forces associated with the contact patch rail transition occurs.

Various models of S\&C have been established to evaluate the influence of changes in support. For example, Xu et al. [6] developed a finite element (FE) model showing that composite stiffness varies up to 2.2 times greater than plain line. An FE model calibrated against in situ composite stiffness measurements showed stiffness variations up to 1.7 times that of plain line [7]. Both of these studies assumed a constant trackbed stiffness, so that the variation in composite stiffness resulted purely from changes in superstructure characteristics. However, the effective trackbed stiffness, taking into account any gapping between the bearer base and the underlying ballast, may vary significantly [8]. At S\&Cs, the trackbed stiffness is likely to vary more dramatically than on plain line owing to greater vertical impact loads and poor / non-uniform maintenance.

Modelling accounting for variations in trackbed stiffness requires in situ measurements on a per bearer basis for calibration and / or validation. However, such in situ measurements are scarce. An investigation carried out during the European project, INNOTRACK [9], used the Banverket Rolling Stiffness Measurement Vehicle (RSMV) $[10,11]$, which is able to make overall dynamic measurements at $60 \mathrm{~km} / \mathrm{h}$ and more detailed measurements at $10 \mathrm{~km} / \mathrm{h}$ with excitation frequencies up to $50 \mathrm{~Hz}$.

Measurements of stiffness from rolling devices give the composite trackbed stiffness (dynamic values in the case of RSMV, static values in the case of devices developed in China [12] and USA [13]), calculated from the measured displacement under a known axle load [11]. Owing to local variations such as missing or aged rail and/or baseplate pads, it may not be as straightforward to separate the influence of the trackbed from that of the fixing system and superstructure on a per bearer basis as on plain line [14].

A common method for counteracting rapid changes in trackbed stiffness is to adjust the track resilience, for example by using soft rail-pads, baseplates, Under Sleeper Pads (USPs) or ballast mats [15]. By including additional compliance, the composite stiffness may be lowered and, at least in principle, made less variable. Some recent studies have used time domain vehicle-track interaction models to address a particular failure type through quantification of damage indices and optimising the system stiffness profile (e.g. [16], [4], [17], [18]). However, there has been no attempt to link the longitudinal variation in support conditions to the wheel-rail contact behaviour at S\&C. Current 
modelling approaches rarely incorporate or are validated using real measurements of track behaviour. Thus their accuracy is uncertain and the true variation in wheel-rail contact forces may be under- or over-estimated. This study aims to develop validated S\&C models using real track measurements from an S\&C site incorporating USPs, and to interrogate the models to gain new insights into S\&C performance.

Two modelling approaches are presented within this paper: one based on commercial multibody system (MBS) software and the other an independent FE vehicle-track model. Both include the variation in trackbed stiffness at each bearer location through the switch panel and the crossing panel. Its variation has been back-calculated from in situ measurements of selected bearer movements at an in-service S\&C. The ability of the models to capture accurately the measured field behaviour is assessed, and key outputs of the models are compared to provide insights into the key mechanisms of behaviour. The variation of dynamic load through the S\&C resulting from the variation in trackbed and composite track stiffness is captured, and the influence of USPs is discussed.

\section{Field study site and measurement methods}

\section{1. $\quad$ Field site}

The complete site was described by Le Pen et al. [19] .This paper focuses on a section of the site, comprising two mainline tracks with a speed limit of $177 \mathrm{~km} / \mathrm{h}$ (49 m/s). These are named the Up and Down lines, following standard UK practice. The S\&C begins just after a concrete-reinforced masonry underbridge (Figure 1).

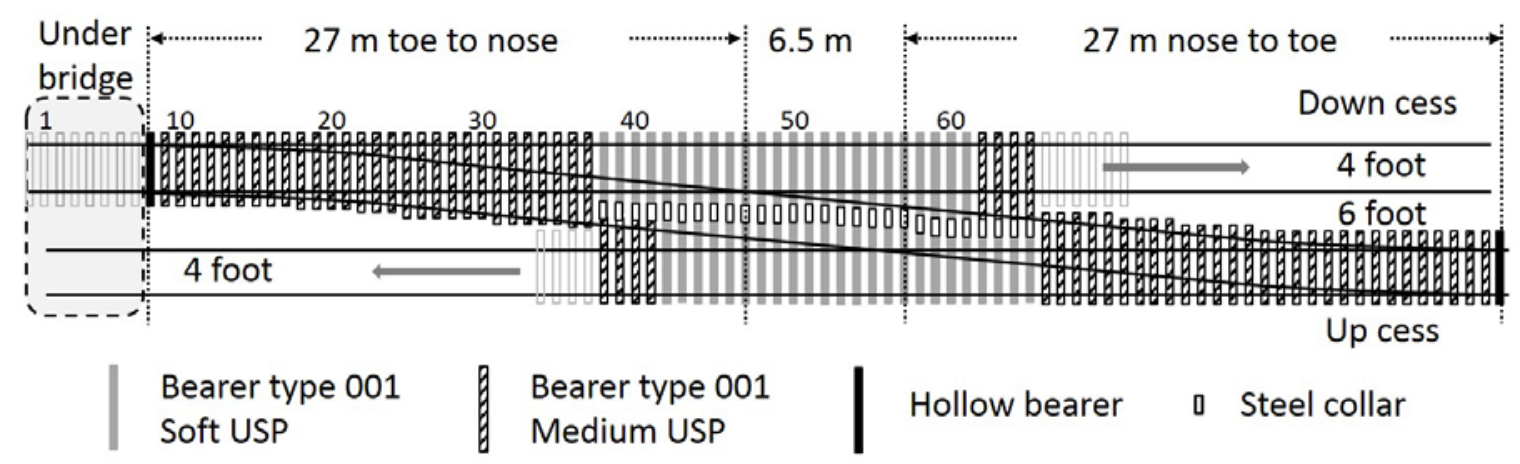

Figure 1: Site overview. The numbered bearers identify monitored locations (Le Pen et al. [19]).

Figure 1 shows a numbering system for bearers along the Down main line. As per UK convention, the 4 foot $(4 \mathrm{ft})$ is the area between the rails on each line; the 6 foot $(6 \mathrm{ft})$ is the area between a pair of lines; the Up cess is the area adjacent to the Up line on the side furthest from the Down line, and vice versa for the Down cess.

The crossing angle is 1 in 13. Twist rails transition the rail from 1 in 20 to vertical. The bearers are concrete type G44 sleepers spaced at $650 \mathrm{~mm}$ centres and type 001 for the length of the crossover. Figure 2(a) shows the switch panel and Figure 2(b) shows the two crossing panels on both tracks viewed from the underbridge. The track gauge is 1435 $\mathrm{mm}$, except through the crossover where it reduces to $1432 \mathrm{~mm}$. The rails are CEN56E1 
and CEN56E1A1 (vertical). The crossing includes several long concrete (001) bearers, which prevent differential lateral movement of the two tracks. The long bearers are formed from two parts, connected by a bolted steel collar (Figure 2(b)) - a Network Rail (UK) approved design that restricts relative movement and rotation at the joint.

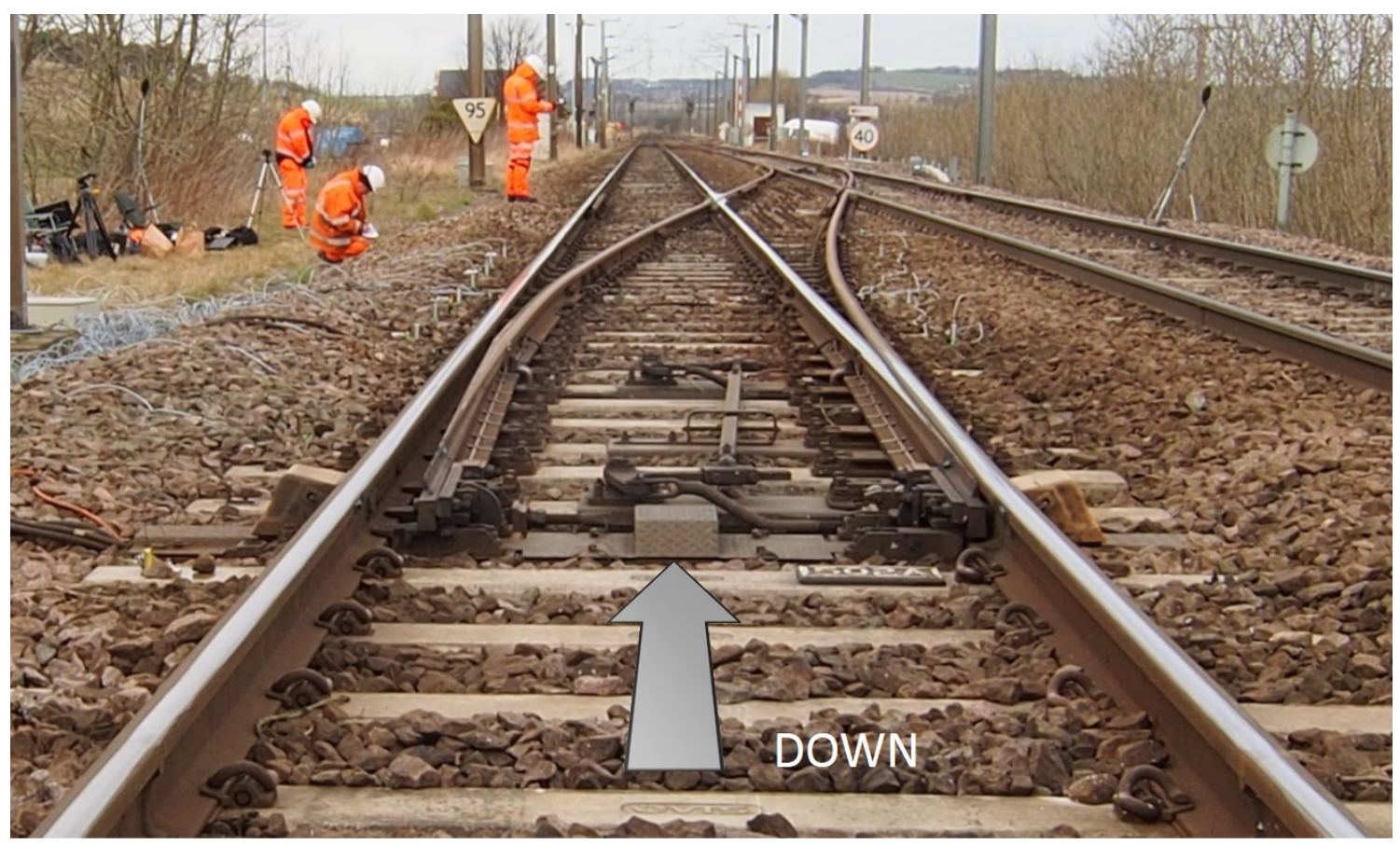

(a)

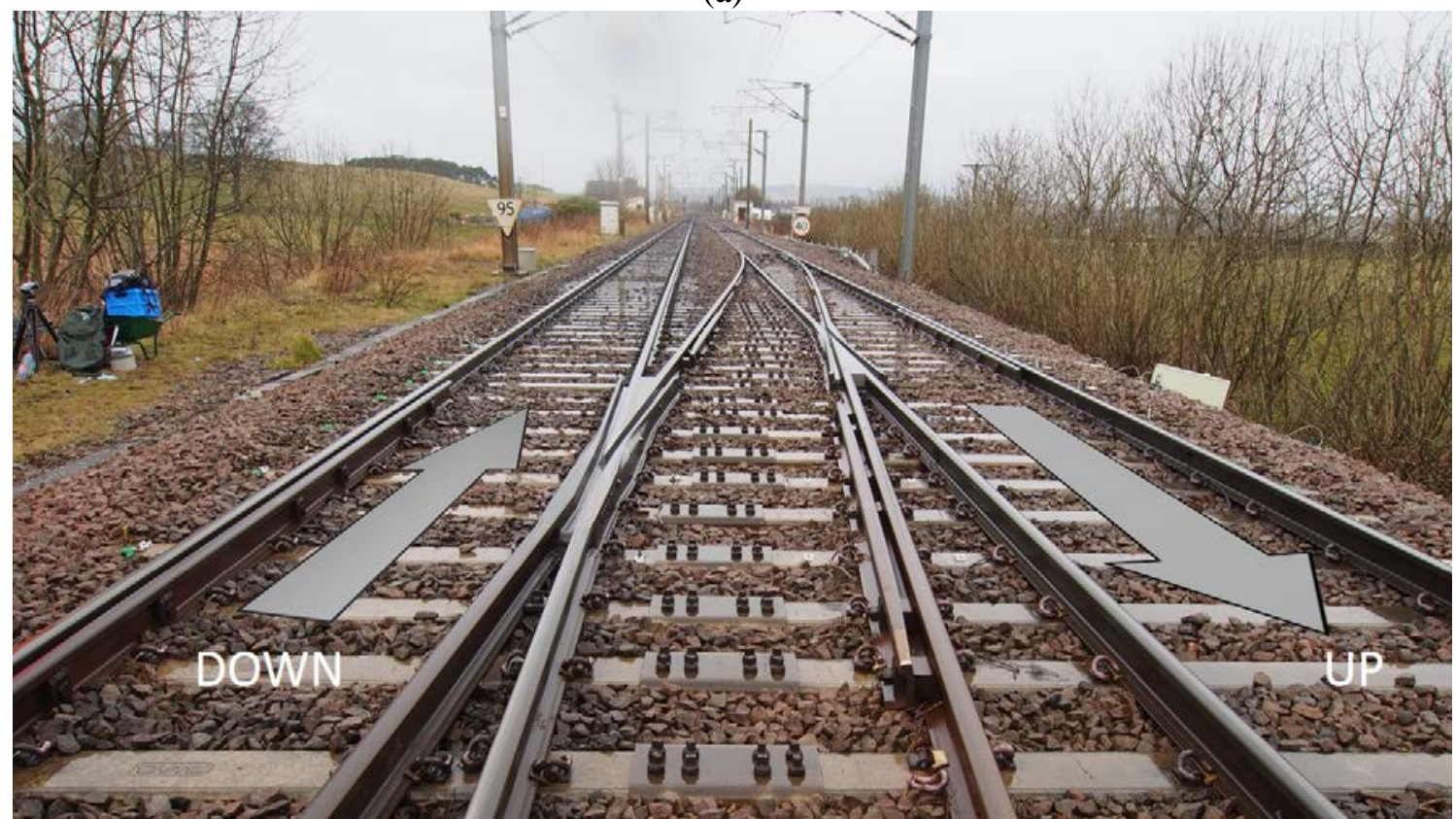

(b)

Figure 2: (a) The switch panel and (b) the two southern section crossing noses. Both photographs are taken from the underbridge end, looking north.

The track at the study site was renewed in December 2012, when the rails, sleepers / bearers and $300 \mathrm{~mm}$ of ballast were replaced. Two types of USPs were fitted during the 
renewal (Figure 1). The different USP types were intended to smooth the change in trackbed stiffness over the transition to and from the long bearers. USPs were placed over the full length of the jointed concrete bearers; four sets of bearers on either side of the crossing nose were fitted with one type of USP on one side and a different type on the other.

The behaviour was expected to be typical of S\&C on the UK network, although the presence of USPs will increase the range of resilient movement.

The USPs are manufactured from polyurethane and are described as soft or medium [20]. They have a thickness of $10 \mathrm{~mm}$ and $C_{\text {stat }}$ [21] values of $0.15 \mathrm{~N} / \mathrm{mm}^{3}$ and $0.22 \mathrm{~N} / \mathrm{mm}^{3}$ respectively. Previous laboratory testing and field measurements have shown how USPs increase the resilient range of movement [19, 22].

This study focuses on the through route of the Down line. There are several key locations as the train passes along the Down route where dynamic loading is likely to be significant and track system properties vary. The train enters the switch panel at approximately bearer 8 (Figure 1). The wheel on the $6 \mathrm{ft}$ side transfers from the stock rail to the switch rail (Figure 2(a)) between bearers 11 and 17. The switch rails curve from bearer 8 to meet the crossing noses at bearer 47 (Down) and 52 (Up). These switch rails increase the local track system bending stiffness. Check rails, which also increase the system bending stiffness, are present between bearers 41 and 49 of the down route. The rail section is also locally greater around the crossing nose.

\subsection{Field measurements}

Selected bearers were monitored over the course of a few days in March 2016. The deployment is more fully described in [19] and only summary details are provided here. The monitoring was carried out using twenty vertically-oriented geophones simultaneously recorded at $500 \mathrm{~Hz}$ using two data loggers with 10 channels each. The geophones and loggers were moved between locations to cover a greater proportion of the bearers at the site, monitoring results from 30 geophone locations are reported in this paper. During monitoring, the crossings were used only in the through directions. The use of the geophones to measure sleeper / bearer vertical velocities during train passage followed established practice (e.g. [8], [23], [24], [25]). Instrumentation location plans are shown in Figure 3. 


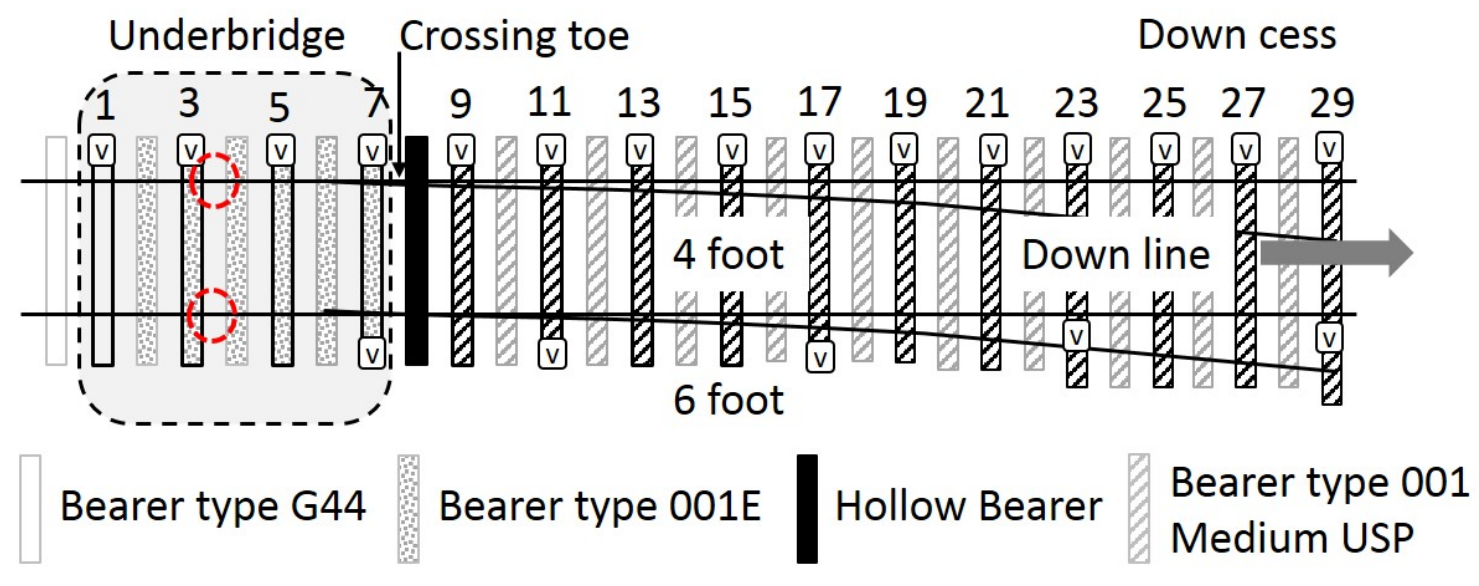

v Vertical geophone

(Sail Weld(s)

(a)

$\begin{array}{llllllllllllll}39 & 41 & 43 & 45 & 47 & 49 & 51 & 53 & 55 & 57 & 59 & 61 & 63 & 65\end{array}$

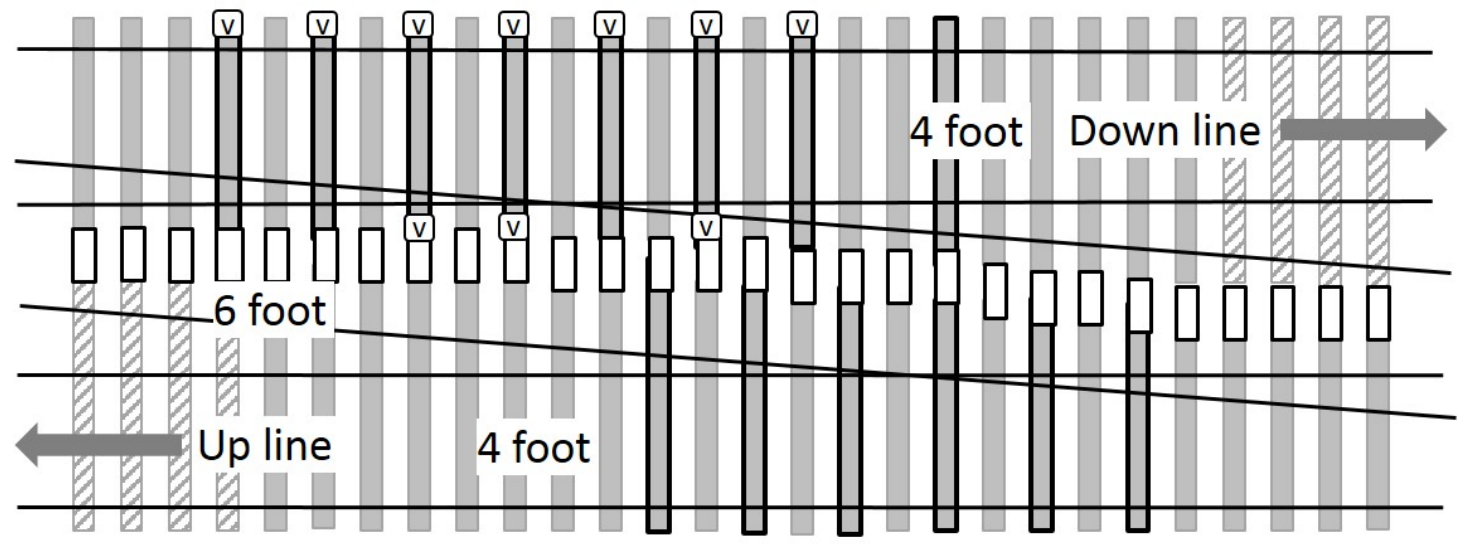

Bearer type 001

Soft USP

\section{Bearer type 001 \\ Medium USP}

Steel collar

(b)

Figure 3: The location of instrumentation at (a) the switch panel and (b) the crossing panel.

A train type on this route is a Class 91 locomotive hauling nine Mark IV coaches and a Driving Van Trailer (DVT). Figure 4(a) shows an example deflection vs time trace for this, determined from geophone data, with the time axes adjusted so that the units are in multiples of Mark IV coach passes. Figure 4(b) shows a theoretical trace calculated using the beam on elastic foundation (BOEF) model [26] using publicly available vehicle data and a support system modulus of $10 \mathrm{MPa}$. 


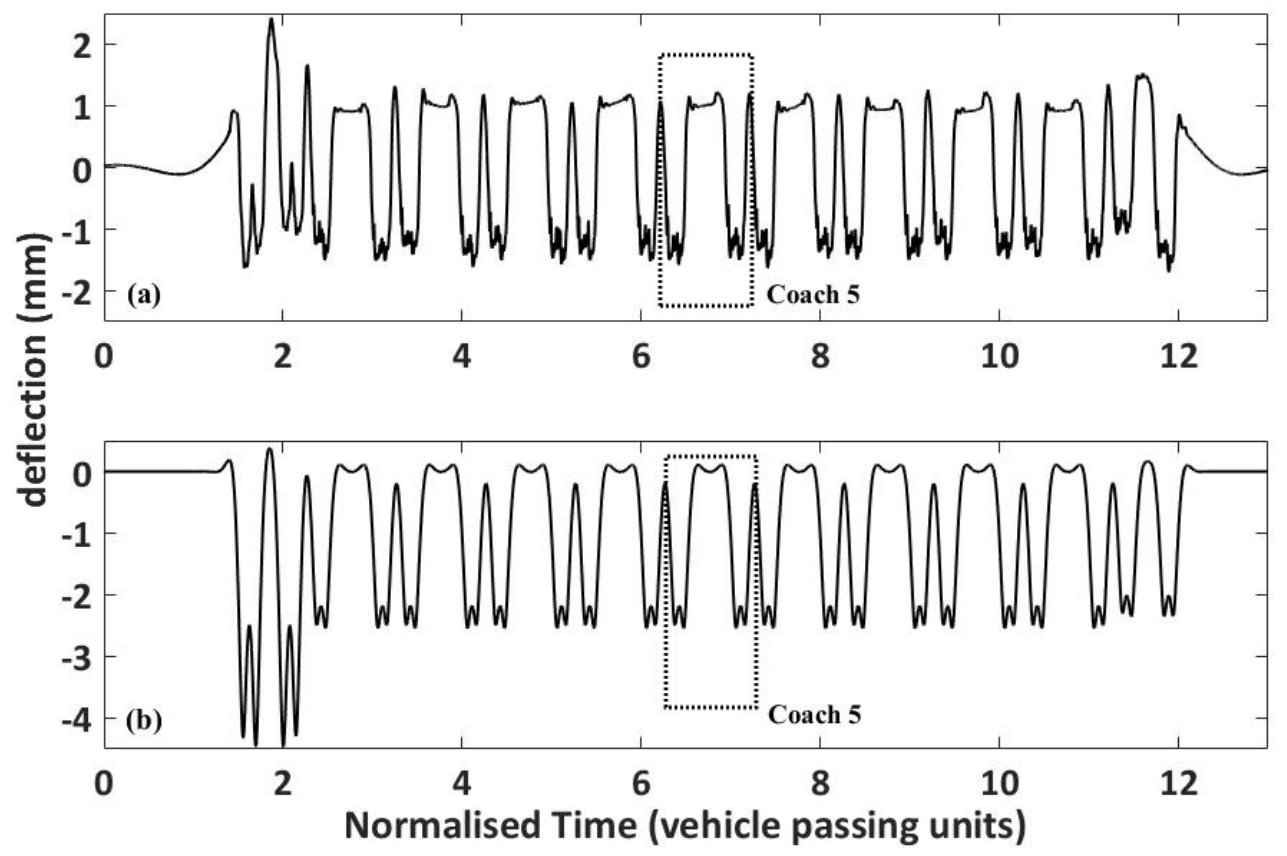

Figure 4: Deflection time trace for a Class 91 locomotive hauling Mark IV coaches and a DVT (a) measured at Bearer 3, cess (Data filtered to remove frequencies below $1.5 \mathrm{~Hz}$ using a Butterworth filter). (b) Theoretical deflection trace for a train speed of $23.4 \mathrm{~m} / \mathrm{s}$ and support system modulus of $10 \mathrm{MPa}$.

The time-deflection trace from the geophone measurements contains artefacts of data processing that cause its general shape to differ from the theoretical trace. Geophones measure velocity, and the signal must be filtered to remove unreliable data from frequencies too far below the natural frequency of the sensor where the sensitivity is nonlinear. Start-up transients affect the leading and trailing bogies quite significantly. Complications in interpreting geophone data also arise when differing vehicle types are present within the train. To interpret the data, the peak to trough (maximum to minimum) movement associated with each axle provides an estimate of the range of movement. Between the passage of the locomotive and that of the DVT, the nine Mark IV coaches provide a repeated pattern of loading and deflection that may be used to infer the relative position of the bearer for each axle with respect to the estimated at rest bearer level (between the bogies as each coach passes). Given these considerations, the most easily interpreted central portion of data corresponding to the passage of the fifth Mark IV coach will be simulated for comparison with the measured data.

The traces shown in Figure 4 match closely. Minor undulations in the time-deflection trace in Figure 4(a) show evidence of higher frequency dynamic vehicle-track interactions. Figure 4(a) uses date from bearer 3, which is removed from the complex features of the $S \& C$. This trace is consistent with the types of trace commonly seen on plain line (e.g. [27]).

Figure 5(a) shows the measured ranges (peak to trough) for bearer movements as axle 3 of the fifth Mark IV coach passes (Figure 4). 

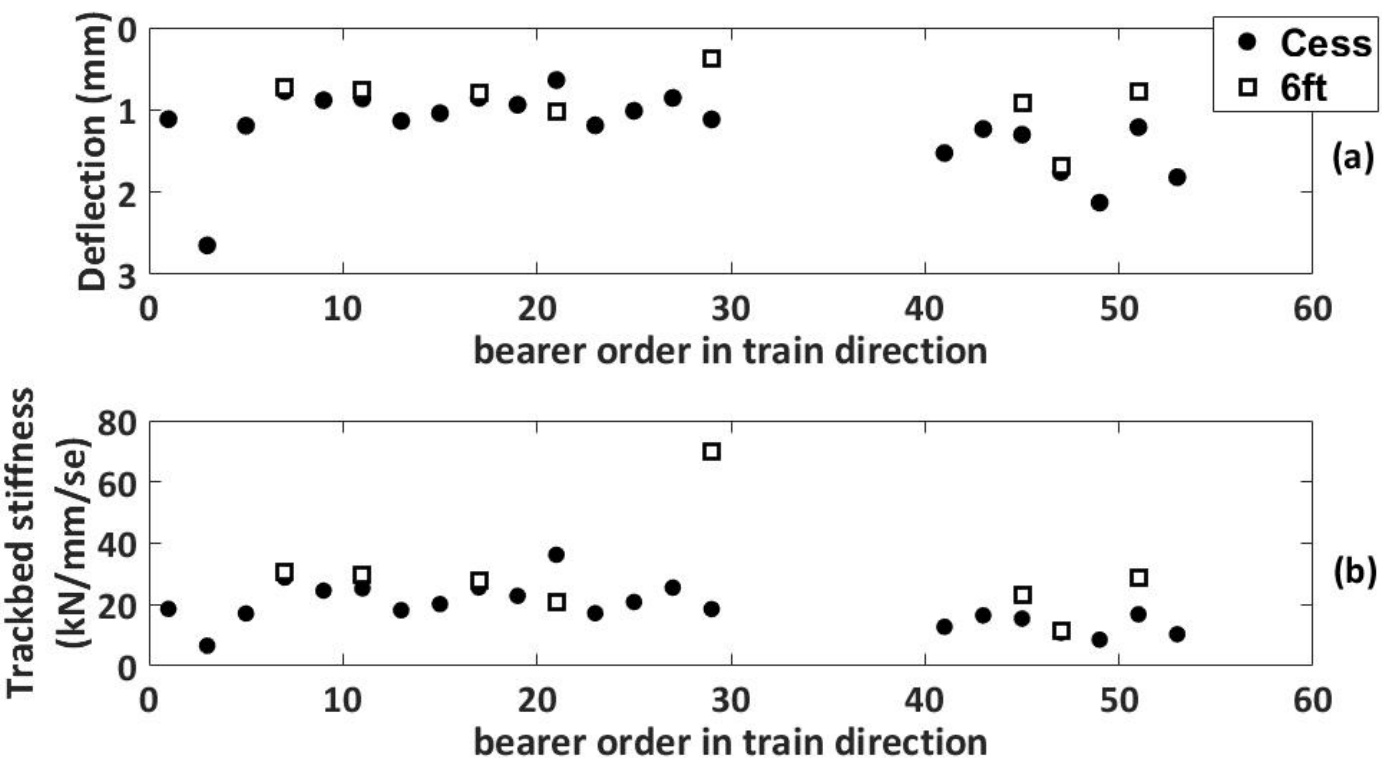

Figure 5: (a) Bearer movements for the third axle of the fifth Mark IV coach (measurements as described in Le Pen et al. [19]). (b) Estimated trackbed stiffness (USPs, ballast and subgrade) based on the fifth coach measured movements and BOEF equations (measurements as described in Le Pen et al. [19]). "Se" refers to "sleeper end".

Track that is performing well will usually show displacements of 0.5-2 mm [3]. Displacements significantly higher than this usually indicate poor support conditions, due either to voids in the ballast beneath the bearer (a 'hanging bearer') or to a very soft subgrade. Larger movements could also be attributed, at least partly, to USPs.

In Figure 5(a), the bearers without USPs (1 to 7) show movements typically in the order of $1 \mathrm{~mm}$, apart from bearer 3. Movements in excess of $2.5 \mathrm{~mm}$ indicate that this bearer may be voided, possibly as a result of dynamic effects associated with the changing support condition in the area of the underbridge, the presence of a weld, the twist rail bringing the rail to vertical and possibly varying support conditions on the aged bridge.

The bearers with medium USPs (9 to 29) also typically move through $1 \mathrm{~mm}$, except for the $6 \mathrm{ft}$ side of bearer 29 , which moves only about $0.3 \mathrm{~mm}$. This is the longest bearer without a joint and supports an additional two crossing rails, so that the additional bending stiffness from the four rails may be providing a locally higher composite track stiffness. The bearers with soft USPs (41 to the end) typically move through $1.5 \mathrm{~mm}$ at the cess side, but there is a greater variation. These bearers are also long bearers tying the two tracks together, and are close to the crossing nose with its associated dynamic loading effects. Displacements measured on the $6 \mathrm{ft}$ side of bearers near to the crossing (45, 49 and 51) tend to be less than on the cess side of the same bearer. This may be ecause these long bearers provide an effectively stiffer support to the $6 \mathrm{ft}$ side of the Down track and also because of the additional bending stiffness of the rail section near to the crossing nose.

The measured movements and an assumed wheel load (57760 N) can be used with the BOEF equations to estimate a trackbed modulus representing the USPs, the ballast and 
the underlying soils. This may be converted to a trackbed stiffness by multiplying by the sleeper spacing $(0.65 \mathrm{~m})$. The results are shown in Figure 5(b).

Figure 5(b) shows that the trackbed stiffness for the bearers without USPs and bearers with medium USPs is typically between $20 \mathrm{kN} / \mathrm{mm} / \mathrm{se}$ and $40 \mathrm{kN} / \mathrm{mm} / \mathrm{se}$. For the bearers with soft USPs, the stiffnesses on the cess side are between $10 \mathrm{kN} / \mathrm{mm} / \mathrm{se}$ and 20 $\mathrm{kN} / \mathrm{mm} / \mathrm{se}$, while the stiffnesses on the $6 \mathrm{ft}$ side are higher, particularly for bearer 29 . These estimates do not take into consideration the dynamic load or the change in track superstructure characteristics (i.e. the second moment of area of the rail is assumed to be constant and equal to that of a standard rail section).

\section{Vehicle-track interaction models at S\&C}

Two different models describing the dynamic behaviour of the Mark IV coach over the S\&C in the through direction are presented. One has been developed in the commercial MBS software VI-Rail using the FlexTrack toolkit [28-30], taking advantage of detailed vehicle modelling capabilities and advanced wheel-rail contact algorithms. The second is an independent model developed in Matlab [18], which features a more accurate representation of the rails but uses a simplified vehicle load model.

\subsection{Modelling the vehicle-track interaction using MBS}

The 2012 renewal plan was used to define the S\&C geometry in AutoCAD for both the through and diverging route, considering all rails and bearer positions. Sleepers outside the installation plan were added assuming a constant spacing of $0.65 \mathrm{~m}$.

The rails were modelled as rigid bodies with concentrated mass and inertia above each bearer [31]. Each rail was connected longitudinally to adjacent rail parts through a massless Timoshenko beam of uniform cross-section, with 1e-4 Rayleigh damping. Five degrees of freedom (DOFs) were considered at each rail element above the bearer; vertical ( $z$ ) and lateral $(y)$ movement and rotation around the $x$ (roll), $y$ (pitch) and $z$ (yaw) axes. The bearers were modelled as rigid bodies with three DOF each; lateral and vertical translation and roll rotation. The rail-pads and the support were modelled as linear springdashpot elements, with stiffness and damping in the three directions. The total number of bearers considered was 108. Two additional rigid sections (i.e. a $22 \mathrm{~m}$ long section before the flexible track and a $7 \mathrm{~m}$ long section after it) were included.

A detailed model of the Mark IV passenger coach was built in VI-Rail. A non-Hertzian (i.e. non-elliptical) contact patch shape and a multiple contact algorithm able to accommodate variability in rail shape in the switch and crossing panels was used [32]. As-new geometry was assumed, specified through a series of 2D cross sections at 20-50 $\mathrm{mm}$ spacing in areas of rapid change. An on-line 3D interpolation algorithm to calculate the rail shape at each iteration step for each wheel-rail contact was used to model rapid changes in contact conditions and transient load between the vehicle and the track in the switch and crossing panels. 
The following simplifying assumptions were made in the VI-Rail model:

1. An independent switch rail beam, starting from the position at which its head width is equal to the stock rail head width, was specified. Up to that point, a single beam representing the combined switch-stock assembly was considered, with beam properties assumed to increase linearly along its length.

2. In the crossing panel, the variable properties of the crossing element were approximated using two intersecting plain line rails, rigidly connected at discrete nodes to account for the effective increased stiffness of the casting.

3. The long bearer connection was assumed to be rigid (see Figure 6(b)). The second point is an approximation subject to further work, beyond the scope of this paper.

\subsection{Modelling the vehicle-track interaction using FEA}

A three-dimensional vehicle-track interaction model (VTI) was established in Matlab [18]. The rail-pad and the trackbed resilient layers were represented using linear spring / dashpot elements in two-layer, discretely supported ballasted track model. Each rail node had DOF: vertical ( $z$ ) and lateral ( $y$ ) displacement, and rotations about the $y$ and $z$-axes (rail roll was neglected). To model the abrupt change in the crossing geometrical properties, four Timoshenko beam elements were included within each bearer-spacing; the minimum needed to describe frequency content up to $800 \mathrm{~Hz}$, as specified in Shih [33]. The bearers were modelled as rigid bodies with three DOF (vertical and lateral displacement, and roll rotation).

Vehicle loading was approximated using two rigid single axles on one bogie. Each axle had four DOF (vertical and lateral displacement; roll and yaw rotation). Linear primary suspensions connected each wheelset to a rigid point following the frame of reference of the track centreline.

The following additional assumptions were made in implementing the FE model in Matlab:

1. Only the through route was considered.

2. In the switch panel, a similar approach to the VI-Rail model was adopted with two rails and two rail-pads per side considered from bearer 8.

3. The bearer length and spacing were constant along the track.

4. In the crossing panel, an equivalent roll spring (see Figure 6(a)) was used to replicate the roll resistance of connected long bearers along the panel, calculated as the product of the stiffness at each support side in the up line (i.e. $k_{3 V}$ and $k_{4 V}$ in Figure 6(b)) and the distance of each support end to the connection joint (i.e. $a$ and $b$ ).

\subsection{Summary of models assumptions and input data}


Table 1 compares the key features of the two modelling approaches.

Table 1: Comparison of the main characteristics of the two modelling approaches.

\begin{tabular}{l|l|l}
\hline & \multicolumn{1}{|c}{ VI-Rail } & \multicolumn{1}{c}{ VTI } \\
\hline Vehicle & Full vehicle model & $\begin{array}{l}\text { 2 axles with primary yaw } \\
\text { stiffness }\end{array}$ \\
\hline $\begin{array}{l}\text { Discretisation of the rail } \\
\text { between consecutive sleepers }\end{array}$ & 1 element & 4 elements \\
\hline Beam approach & $\begin{array}{l}\text { Concentrated masses on top of } \\
\text { sleepers linked through mass- } \\
\text { less Timoshenko beams }\end{array}$ & Timoshenko beam \\
\hline Variation of rail section profiles & Yes & Yes \\
\hline Variation of rail properties & Coarse and indirect & Yes \\
\hline Bearer & Rigid body as in Figure 6(b) & $\begin{array}{l}\text { Rigid body as in Figure 6(a) } \\
\text { with the equivalent } \\
\text { rotational bushing }\end{array}$ \\
\hline Sleeper spacing & Variable & Constant \\
\hline Track irregularities & Included in the calculations & Included in the calculations \\
\hline Long bearer connection & Rigid connection & Rigid connection \\
\hline Vertical contact theory & Non-Hertzian contact theory & Hertzian contact theory \\
\hline No. points of contact & Up to 10 & 1 \\
\hline
\end{tabular}

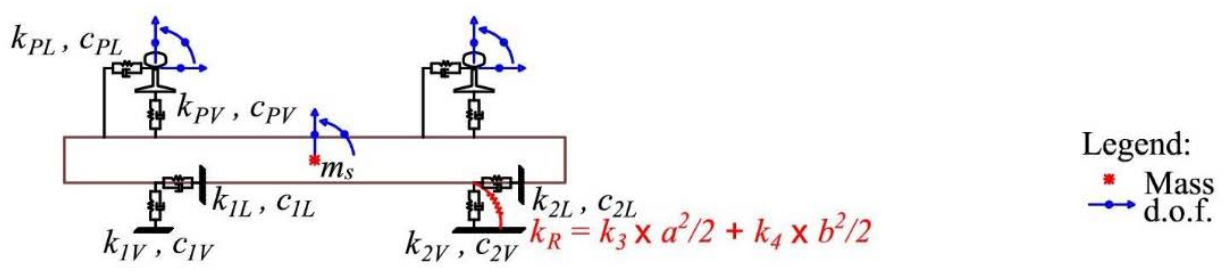

(a)

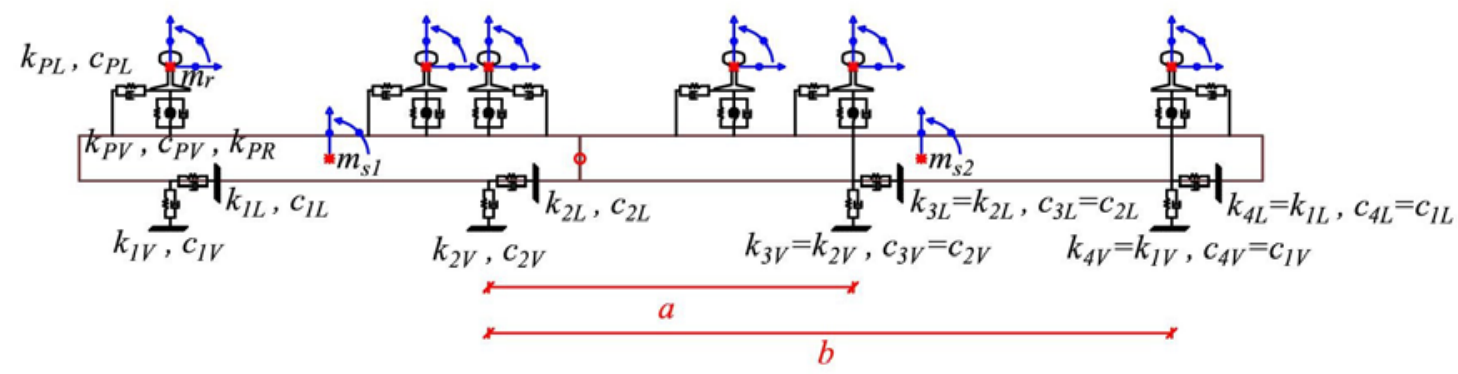

(b)

Figure 6: Transversal cross section of a long bearer in the (a) VTI model and (b) VI-Rail, showing position of support force elements for ballast and rail-pads.

The main track input parameters are summarised in Table 2. 
Table 2: Track input parameters.

\begin{tabular}{|c|c|c|}
\hline Parameter & Value & Unit \\
\hline Rail profile & \multicolumn{2}{|l|}{ 56E1 } \\
\hline Steel Young's modulus & 210 & GPa \\
\hline Steel density & 7850 & $\mathrm{~kg} / \mathrm{m}^{3}$ \\
\hline Concrete density & 2400 & $\mathrm{~kg} / \mathrm{m}^{3}$ \\
\hline Rail-pad vertical stiffness & $70.0^{\dagger}$ & $\mathrm{kN} / \mathrm{mm} /$ sleeper end \\
\hline Rail-pad lateral stiffness & 60.0 & $\mathrm{kN} / \mathrm{mm} /$ sleeper end \\
\hline Rail-pad vertical damping ratio & 0.3 & - \\
\hline Rail-pad lateral damping ratio & 0.5 & - \\
\hline Trackbed vertical stiffness (plain line no USP) & $40^{\ddagger}$ & $\mathrm{kN} / \mathrm{mm} /$ sleeper end \\
\hline Trackbed lateral stiffness (plain line no USP) & 10 & $\mathrm{kN} / \mathrm{mm} /$ sleeper end \\
\hline Trackbed vertical stiffness (switch panel) & \multicolumn{2}{|c|}{ See Section 4} \\
\hline Trackbed lateral stiffness (switch panel) & \multicolumn{2}{|c|}{ See Section 4} \\
\hline Trackbed vertical stiffness (crossing panel) & \multicolumn{2}{|c|}{ See Section 4} \\
\hline Trackbed lateral stiffness (crossing panel) & \multicolumn{2}{|c|}{ See Section 4} \\
\hline Trackbed vertical damping ratio & 1.0 & - \\
\hline Trackbed lateral damping ratio & 1.0 & - \\
\hline Soft USP vertical stiffness ${ }^{\S}$ & 53.5 & $\mathrm{kN} / \mathrm{mm} /$ sleeper end \\
\hline Soft USP lateral stiffness & 13.4 & $\mathrm{kN} / \mathrm{mm} /$ sleeper end \\
\hline Soft USP vertical damping ratio & 0.2 & - \\
\hline Soft USP lateral damping ratio & 0.2 & - \\
\hline Medium USP vertical stiffness ${ }^{* *}$ & 78.5 & $\mathrm{kN} / \mathrm{mm} /$ sleeper end \\
\hline Medium USP lateral stiffness & 19.6 & $\mathrm{kN} / \mathrm{mm} / \mathrm{sleeper}$ end \\
\hline Medium USP vertical damping ratio & 0.2 & - \\
\hline Medium USP lateral damping ratio & 0.2 & - \\
\hline
\end{tabular}

The trackbed stiffness includes all elements below the bearers, including the USP if present, the ballast and subgrade. In both numerical models, symmetry along the track centre line was assumed below the crossing panel, i.e. the same stiffness values were assigned to both tracks.

\section{Tuning the model trackbed vertical stiffness}

The models were calibrated by tuning an initial estimate of trackbed stiffness to best match the field measurements. This iterative procedure was performed using the VTI model, with the same input parameters then used for both models.

\footnotetext{
† This value is in the low side of the rail-pad stiffness range.

‡ This value is a reasonable starting estimate (e.g. [4]).

$\S$ These values have been estimated using the $\mathrm{C}_{\text {stat }}$ modulus and the bearer bottom area.
} 
For the switch panel, tuning was initiated by assigning the estimated trackbed stiffness (Figure 5). For the crossing panel, tuning was initiated using a reference bearer (51) such that the trackbed stiffness at each other bearer was is proportion with the reference deflection.

The VTI model was then run to calculate the wheel-rail dynamic forces and the resulting bearer displacements. The percentage difference between the numerical and measured displacements was calculated and the same percentage difference was applied to the trackbed stiffness. The updated stiffness distribution was then re-run iteratively until the average percentage difference at all of the bearer ends was less than $7 \%$, a suitable tradeoff between computational time and accuracy.

Owing to gaps in the measured data some simplifying assumptions were also applied. On the switch panel, only the cess side was calibrated and the resulting trackbed stiffness applied to the $6 \mathrm{ft}$ side. In the crossing panel, at locations where no measurements were available on the $6 \mathrm{ft}$ side, the same variation as on the respective cess side was assumed. Bearer 41 was disregarded in the tuning process as its deflection is significantly different from the following two measurements, and the current model is not able to replicate this without application of an impulse.

The post-calibration percentage differences between the measured and simulated deflections as well as the trackbed stiffnesses are reported in Table 3. 
Table 3: Percentage difference between simulated data and field measurements and variation of trackbed stiffness along the switch and crossing panel after calibration (all per sleeper end).

\begin{tabular}{|c|c|c|c|c|c|}
\hline \multirow{3}{*}{ Panel } & \multirow{3}{*}{ Bearer } & \multicolumn{2}{|c|}{ Cess } & \multicolumn{2}{|c|}{$6 \mathrm{ft}$} \\
\hline & & $\Delta$ Displ & $\mathbf{K}_{\mathbf{b}}$ & $\Delta$ Displ & $\mathbf{K}_{\mathbf{b}}$ \\
\hline & & [\%] & {$[\mathrm{kN} / \mathrm{mm} / \mathrm{se}]$} & [\%] & {$[\mathrm{kN} / \mathrm{mm} / \mathrm{se}]$} \\
\hline \multirow{15}{*}{ Switch } & 1 & -1.3 & 20.3 & - & 20.3 \\
\hline & 3 & -19.8 & 3.6 & - & 3.6 \\
\hline & 5 & -0.5 & 16.5 & - & 16.5 \\
\hline & 7 (Switch toe) & 1.1 & 27.4 & 14.8 & 27.4 \\
\hline & 9 & -1.4 & 24.2 & - & 24.2 \\
\hline & 11 & 1.6 & 27.6 & 26.2 & 27.6 \\
\hline & 13 & -6.4 & 13.6 & - & 13.6 \\
\hline & 15 & -3.0 & 14.8 & - & 14.8 \\
\hline & 17 & 2.8 & 25.0 & 38.0 & 25.0 \\
\hline & 19 & -9.5 & 19.6 & - & 19.6 \\
\hline & 21 & 17.1 & 39.0 & - & 39.0 \\
\hline & 23 & -16.1 & 10.9 & 0.9 & 10.9 \\
\hline & 25 & -1.0 & 16.1 & - & 16.1 \\
\hline & 27 & - & 27.9 & - & 27.9 \\
\hline & 29 & -6.0 & 12.9 & 193.5 & 12.9 \\
\hline \multirow{6}{*}{ Crossing } & 43 & 3.2 & 23.1 & - & 28.1 \\
\hline & 45 & 5.8 & 21.1 & 3.4 & 28.1 \\
\hline & $\begin{array}{l}47 \text { (Crossing } \\
\text { nose) }\end{array}$ & 1.3 & 18.2 & 4.2 & 13.8 \\
\hline & 49 & 1.2 & 20.4 & - & 6.4 \\
\hline & 51 (Reference) & 10.3 & 44.8 & 1.5 & 26.6 \\
\hline & 53 & 1.1 & 9.8 & - & 16.6 \\
\hline
\end{tabular}

\section{Comparison of the models with field data}

\subsection{Switch panel}

Simulated and measured bearer displacements along the switch panel under both rails are compared and the calculated wheel-rail contact forces are indicated in Figure 7. There is very close agreement between the measured data and both models. 


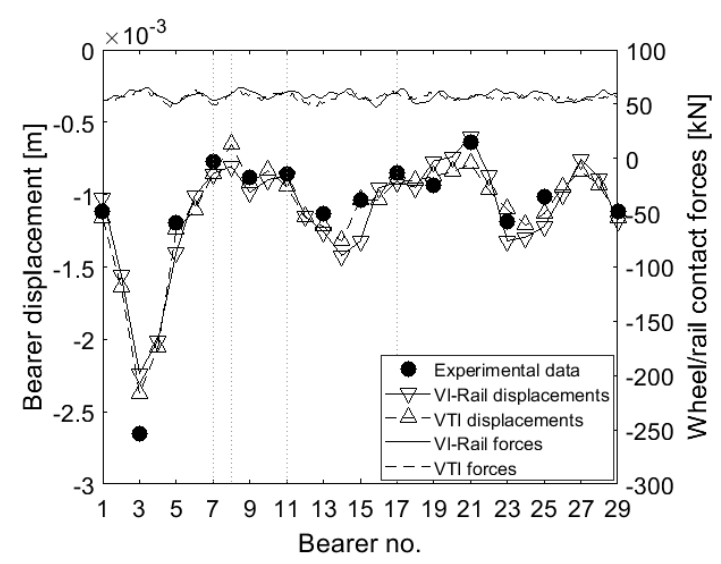

(a) cess

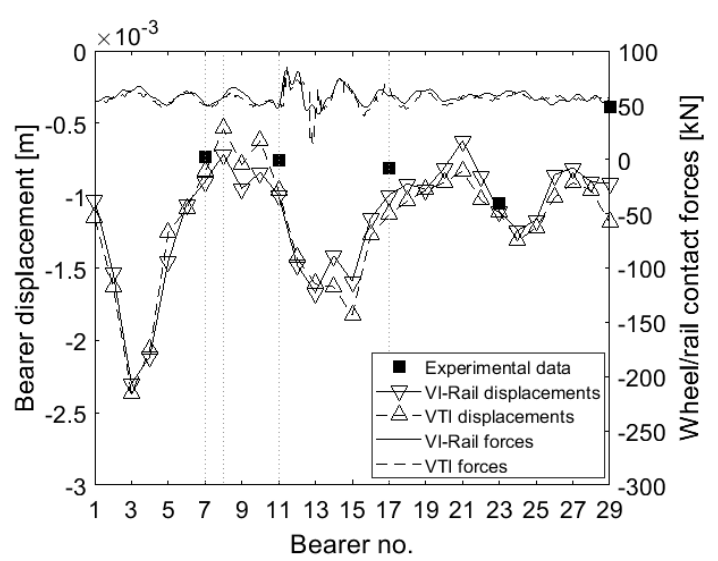

(b) $6 \mathrm{ft}$

Figure 7: Bearer displacement along the switch panel, numerical results and experimental measurements at (a) cess side and (b) $6 \mathrm{ft}$ side.

A soft spot (voided bearer 3) situated a few bearers ahead of the switch toe (bearer 8) causes dynamic load amplification, apparent as an undulation in the load between bearers 3 and 11 (Figure 7 - secondary axis). On the 6ft side, dynamic loads induced by the change in contact conditions during transfer between stock and switch rails (i.e. between bearers 11-17) induce a significant variation in vertical displacement. This is corroborated by in situ observations (see Figure 2(a)). The contact force is up to $46 \%$ greater than the static load, with some of this increase transmitted to the ballast. This increased deflection is also reflected at the cess in the simulation, but is not evident in the field data, although that may be because not enough measurements were taken (e.g. $6 \mathrm{ft}$ bearer ends 12 to 16 ).

Figure 8 and Table 4 compare the results of calculations (bearer displacements and contact forces) made using the VTI model, for cases with and without USPs, and variable rather than constant trackbed support stiffness (i.e. $26.5 \mathrm{kN} / \mathrm{mm} /$ sleeper end). 


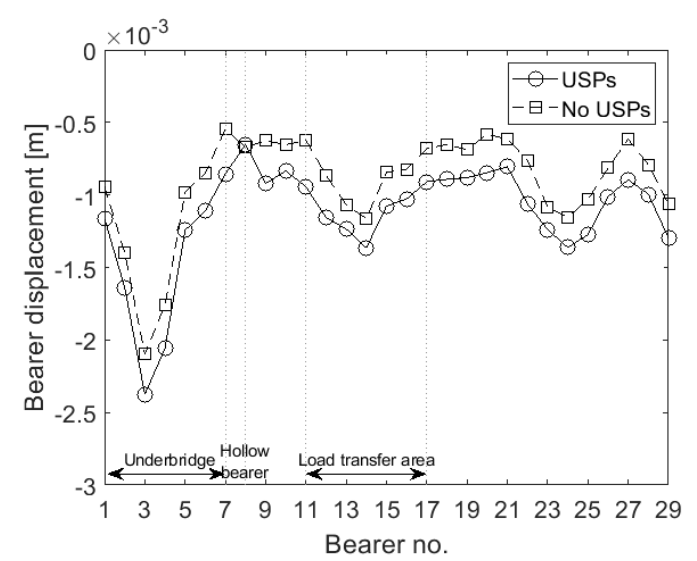

(a) cess

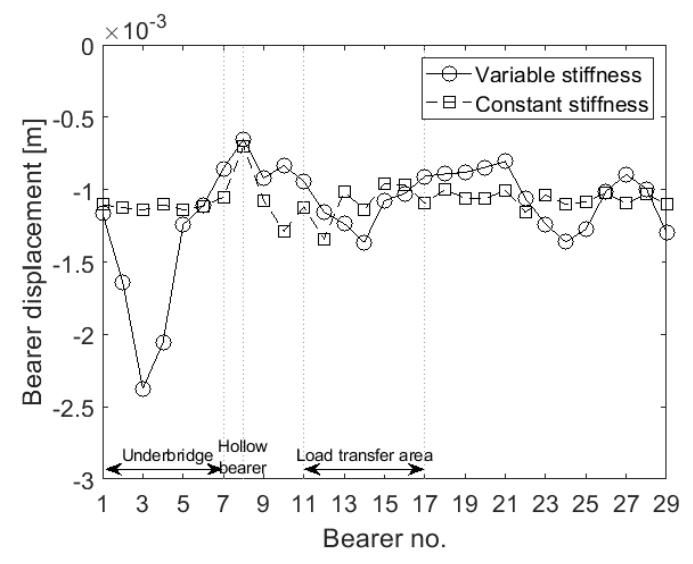

(c) cess

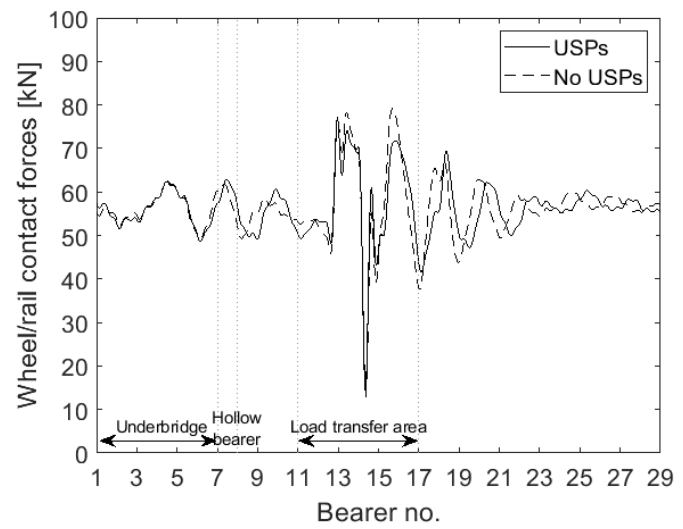

(b) $6 \mathrm{ft}$

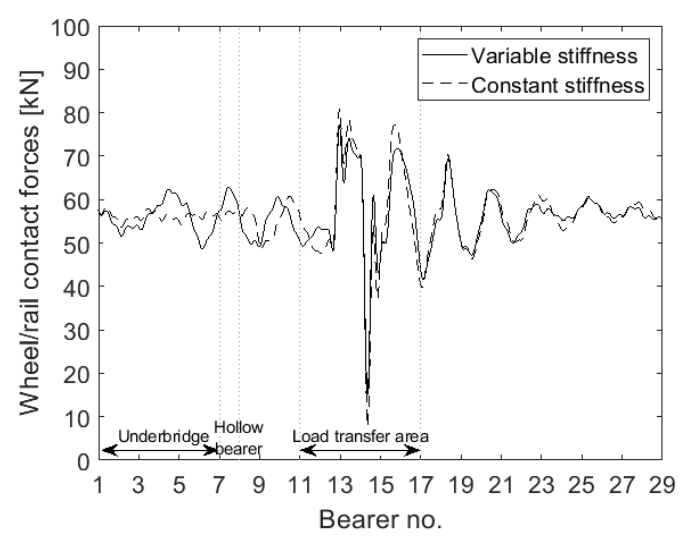

(d) $6 \mathrm{ft}$

Figure 8: Simulated bearer displacements and filtered contact forces below $200 \mathrm{~Hz}$ for cases (a, b) with/without USP and bottom plots (c, d) with/without varying track stiffness.

Table 4: Summary of maximum, minimum and RMS values of contact forces and bearer displacements for the cases analysed.

\begin{tabular}{|c|c|c|c|c|c|c|}
\hline & & \multirow{2}{*}{$\begin{array}{l}\text { Baseline scenario } \\
\text { (USPs and } \\
\text { variable } \\
\text { stiffness) }\end{array}$} & \multicolumn{2}{|c|}{ No USPs } & \multicolumn{2}{|c|}{ Constant stiffness } \\
\hline & & & Value & $\begin{array}{l}\Delta \text { w.r.t. } \\
\text { baseline }\end{array}$ & Value & $\begin{array}{l}\Delta \text { w.r.t. } \\
\text { baseline }\end{array}$ \\
\hline \multirow{5}{*}{$\begin{array}{l}\text { Contact } \\
\text { forces }[\mathrm{kN}]\end{array}$} & Maximum at bearer 4 & 62.5 & 62.5 & $0 \%$ & 56.5 & $-10 \%$ \\
\hline & Maximum at bearer 13 & 74.1 & 78.3 & $6 \%$ & 78.4 & $6 \%$ \\
\hline & Maximum at bearer 16 & 71.8 & 79.0 & $10 \%$ & 77.2 & $8 \%$ \\
\hline & Minimum at bearer 15 & 15.4 & 12.9 & $-16 \%$ & 7.8 & $-49 \%$ \\
\hline & Standard Deviation (1 to 29 ) & 7.9 & 8.9 & $13 \%$ & 9.0 & $14 \%$ \\
\hline \multirow{2}{*}{$\begin{array}{l}\text { Bearer } \\
\text { displacements } \\
{[\mathrm{mm}]}\end{array}$} & Minimum at bearer 3 & 2.374 & 2.097 & $-12 \%$ & 1.141 & $-52 \%$ \\
\hline & Standard Deviation (1 to 29 ) & 0.3678 & 0.3548 & $-4 \%$ & 0.1087 & $-70 \%$ \\
\hline
\end{tabular}

Figure 8(a, b) and Table 4 show that the USPs have a positive effect in smoothing the wheel-rail contact forces, especially along the area of load transfer between switch to stock rails. Not using USPs leads to increases in wheel-rail contact forces of up to $10 \%$, and increases of $13 \%$ in terms of signal standard deviation (SD). A further benefit of USPs is an improved (more extensive and more uniform) contact area between the bearer 
and the ballast (see e.g. [22]), but this was not replicated in the current models. However, the bearer displacement SD increased by nearly $4 \%$ with the USPs, indicating a potential risk for increased geometry variation in an S\&C with soft or medium USPs.

Figure 8(c, d) and Table 4 shows that not considering the actual variation in stiffness leads to slightly different wheel-rail contact force signals, especially in the area of the voided sleeper, and remarkably different bearer displacements. The displacement difference at bearer 3 is up to 52\% w.r.t. baseline scenario and the difference in terms of displacement signal SD over the entire panel is up to $70 \%$. These differences may contribute to important under- or over-prediction of long-term behavioural characteristics of the track when used with numerical simulation tools [14].

\subsection{Crossing panel}

Simulated and measured bearer displacements along the crossing panel under both rails are compared, and the calculated wheel-rail contact forces are indicated in Figure 9 for both numerical models.

Figure 9 shows that both numerical models capture the dynamics at the crossing panel, with an average error less than 7\% (see Section 4). Measured and numerically predicted deflections show close agreement. The bigger differences shown by the VI-Rail model, especially on the $6 \mathrm{ft}$ side, are localised around the crossing nose and can be explained by the differing initial modelling assumptions: VI Rail includes a full long bearer representation, a second track and more sophisticated rail properties (see Table 1).

Considering the deflection data shown in Figure 5(a), and Figure 9(a, b), at the crossing panel (bearers 41 to 53) the measured and predicted deflections are generally significantly greater on the cess side than on the $6 \mathrm{ft}$ side, except very locally to the crossing nose (bearer 47) where the dynamic impact load is greatest (Figure 9(b) secondary y-axis). The deflection measurements are consistent with most long bearers rotating towards the cess when loaded [19] partly due to the support provided from the adjacent track. However, although the simple prediction of trackbed stiffness using constant load and rail properties (Figure 5(b)) showed lower trackbed stiffness at the cess side than at the $6 \mathrm{ft}$ side. The numerically modelled results contradict this and illustrate that when the load and varying rail properties are accounted for, the trackbed stiffness on the cess side of the crossing panel can be greater than the 6ft side (Table 3) even if the deflections are greater on the cess side (Figure 9(a,b)). This is counterintuitive in the sense that larger deflections on plain line imply lower trackbed stiffness. However, at S\&C near the crossing nose, these results may be explained by local increases in the bending stiffness of the track system and the presence of long bearers. The composite track stiffness (which includes the bending stiffness of the rails and the effect of long bearers) is plotted in Figure 10(b), showing how the superstructure of the track system contributes to create a greater composite stiffness seen at the wheel-rail interface, by masking some of the differences between cess and 6ft and locally low support. This plot also clearly shows the significant variability of composite stiffness seen all along the turnout. The loss of trackbed stiffness near the crossing nose, especially under the $6 \mathrm{ft}$ 
(Figure 10(a)), is therefore highly likely to be a result of the high dynamic component of the impact load transfer at the crossing nose, which is recognised to be responsible in parts for support degradation [34]. Lower trackbed support implies that the superstructure will have to take more of the support function, increasing the risk of fatigue failure of casting, which are currently a significant issue for Network Rail in places with their CEN56 crossings.

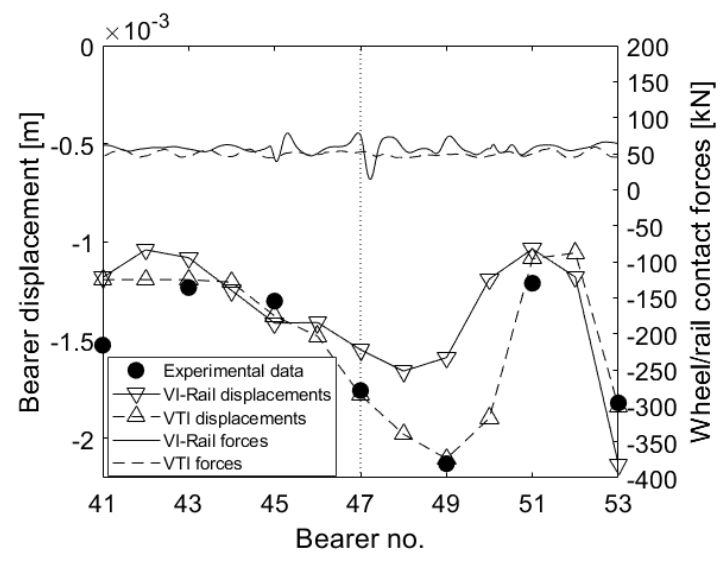

(a) cess

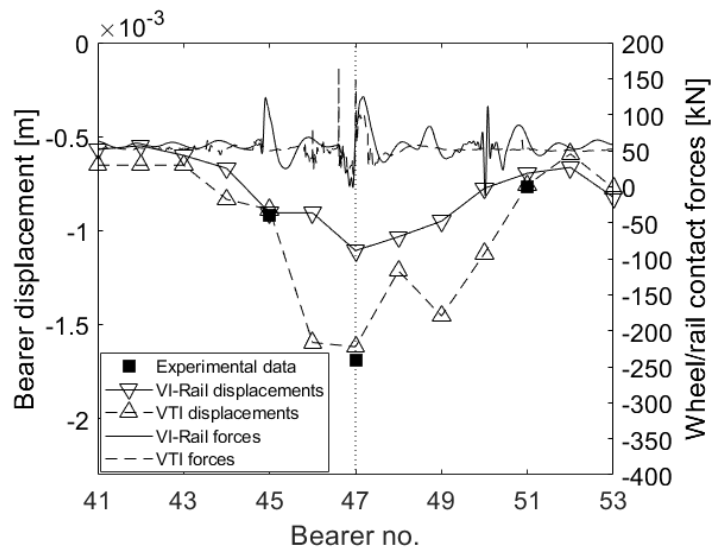

(b) $6 \mathrm{ft}$

Figure 9: Bearer displacement along the crossing panel for numerical models and field measurements at (a) cess side and (b) $6 \mathrm{ft}$ side. The vertical dash-dotted line denotes the crossing nose. 


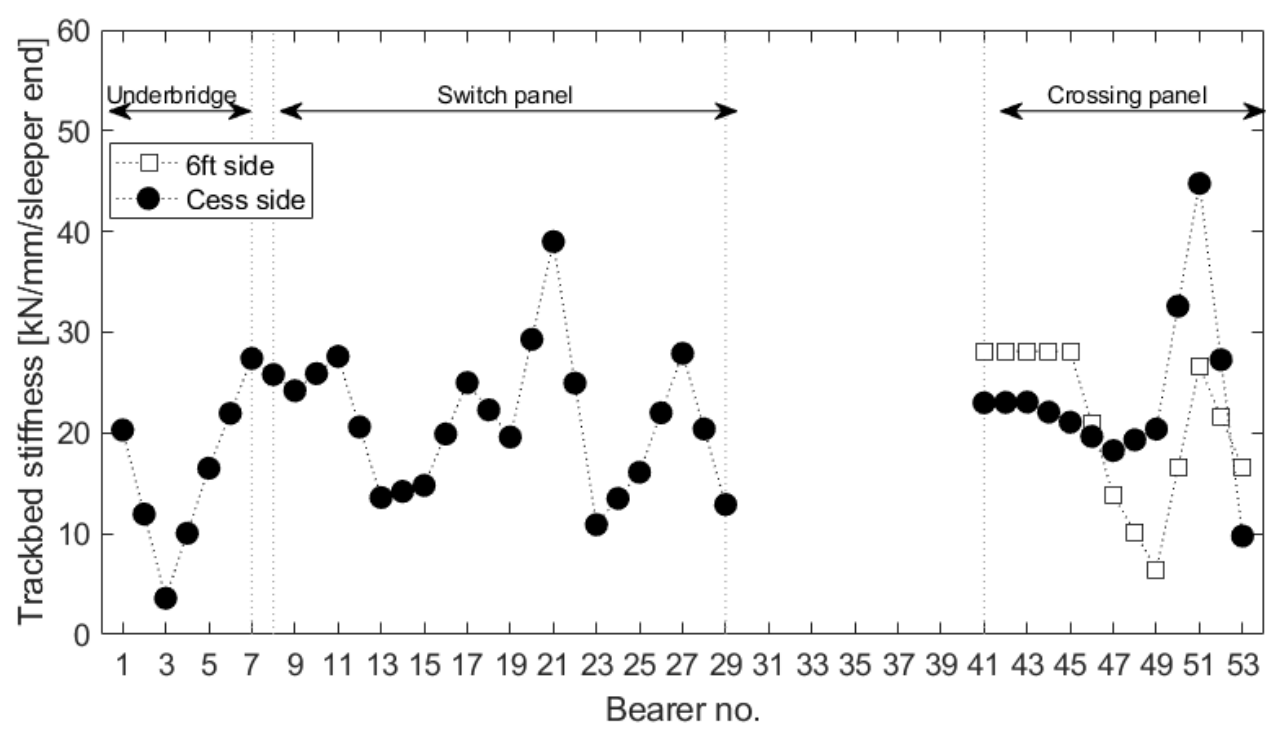

(a)

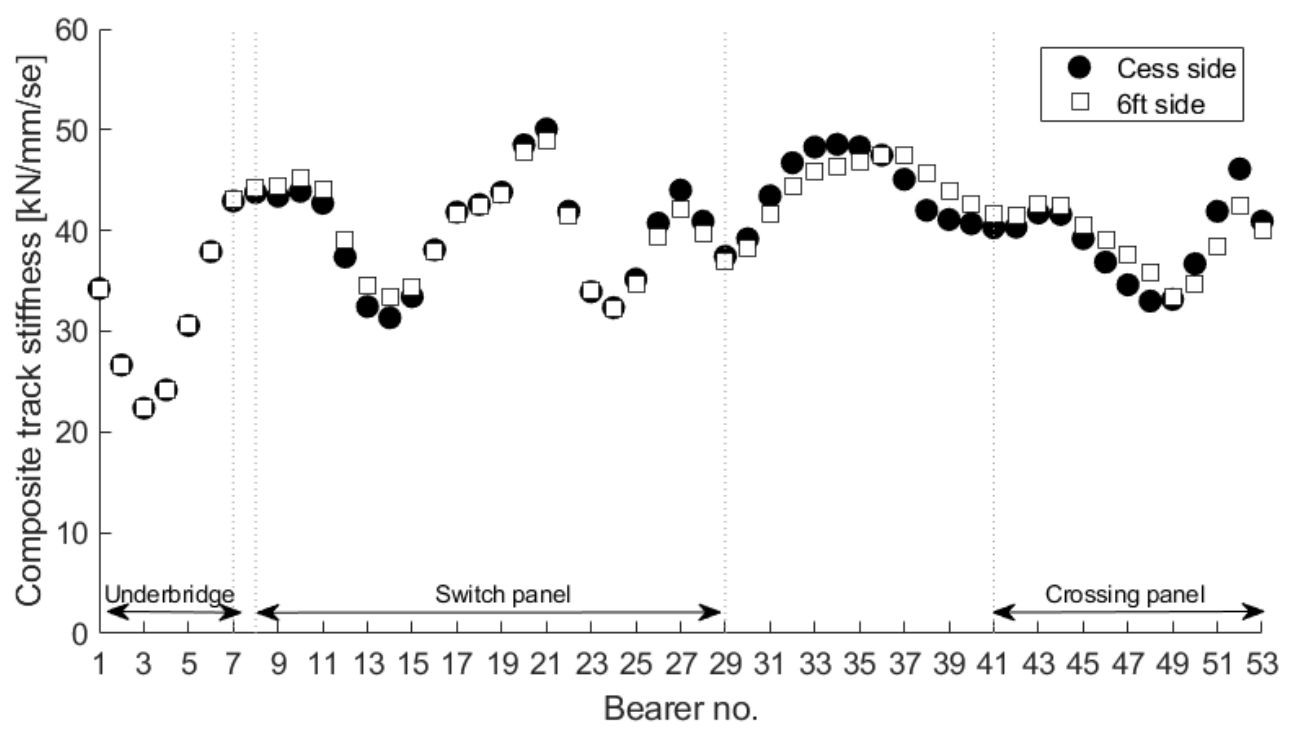

(b)

Figure 10: (a) Tuned trackbed stiffness and (b) calculated composite track stiffness along the S\&C using the VIRail model.

\section{Conclusions}

This paper has developed an understanding of the effect of variation in the trackbed stiffness along an S\&C equipped with USPs, through site measurements and two different numerical models.

The models have enabled an enriched understanding of the measured data, and provided several key insights: 
- At the switch panel, the wheel load transfer from the stock to the switch rail leads to locally increased loads and deflections at specific bearers.

- A soft spot (voided bearer) situated a few metres ahead of the switch toe (bearer 3) just prior to a rail weld was shown to cause dynamic load amplification. The presence of the void could have been due to locally specific conditions but may also illustrate a feature common to all S\&C - more case study sites are needed to confirm this.

- At the crossing panel, the cess displacements are on average higher than the $6 \mathrm{ft}$ with the exception of the $6 \mathrm{ft}$ side of the bearer directly supporting the crossing nose. This is consistent with long bearers rotating towards the loaded side of the track.

- High impact forces were found to be present at the crossing nose and explained a locally higher deflection value. In combination with a locally lower support from the ballast, this increases the risk of fatigue failures for castings.

- Plotting the composite track stiffness shows how the increased bending stiffness of the overall track system near to the crossing nose helps to equalise the composite support stiffness between the two rails and explains why trackbed stiffness estimates based on plain line assumptions are misleading.

- One of the models was additionally used to demonstrate the benefit of the USPs to even out the wheel-rail contact forces, especially around the area of wheel load transfer between the stock and switch rails ( $10 \%$ reduction). However, a slight increase in overall deflection variation (standard deviation) indicates that a more detailed optimisation study would be beneficial.

- Reproducing the actual variation in trackbed stiffness rather than assuming uniform support leads to a different dynamic responses in both models. The dynamic wheelrail force amplification was $\pm 10 \%$. Large deflections under poor support conditions are otherwise missed, and the standard deviation in bearer deflection is under predicted by $75 \%$.

The modelling approaches developed here, together with rigorous site surveys, provide valuable tools to a) help understand complex asset behaviour and condition, and b) support an improved design process for future generation infrastructure.

\section{Acknowledgements}

This work has been funded by the UK EPSRC project Track to the Future (grant agreement no. EP/M025276/1). Track access was provided as support in kind by Network Rail operating through the Strategic University Partnership in Future Infrastructure Systems. Data supporting this study will be made available at online repositories.

\section{References}

1. Kassa, E., C. Andersson, and J.C.O. Nielsen, Simulation of dynamic interaction between train and railway turnout. Vehicle System Dynamics, 2006. 44(3): p. 247-258.

2. Bouch, C., C. Roberts, and J. Amoore, Development of a common set of European highlevel track maintenance cost categories. Proceedings of the Institution of Mechanical Engineers, Part F: Journal of Rail and Rapid Transit, 2010. 224(4): p. 327-335. 
3. Cross Industry Track Stiffness Working Group, A guide to track stiffness. 2016: Southampton.

4. Nicklisch, D., et al., Geometry and stiffness optimization for switches and crossings, and simulation of material degradation. Proceedings of the Institution of Mechanical Engineers, Part F: Journal of Rail and Rapid Transit, 2010. 224: p. 279-292.

5. $\quad$ In2Rail, Deliverable D3.3: Evaluation of optimised track systems. 2017.

6. Xu, J., et al., Stiffness Characteristics of High-Speed Railway Turnout and the Effect on the Dynamic Train-Turnout Interaction. Shock and Vibration, 2016.

7. Li, X., J.C.O. Nielsen, and B.A. Palsson, Simulation of track settlement in railway turnouts. Vehicle System Dynamics, 2014. 52(Suppl.1): p. 421-439.

8. Le Pen, L., et al., Evaluating railway track support stiffness from trackside measurements in the absence of wheel load data. Canadian Geotechnical Journal, 2016. 53(7): p. 11561166.

9. Ekberg, A. and B. Paulsson, INNOTRACK: concluding technical report. 2010: International Union of Railways (UIC).

10. Berggren, E.G., A.M. Kaynia, and B. Dehlbom, Identification of substructure properties of railway tracks by dynamic stiffness measurements and simulations. Journal of Sound and Vibration, 2010. 329(19): p. 3999-4016.

11. Berggren, E., Measurements of track stiffness and track irregularities todetect short waved support conditions. 2006.

12. Wangqing, W., et al. Development of inspection car for measuring railway track elasticity. in Proceedings from 6th international heavy haul conference, Cape Town. 1997.

13. Li, D., R. Thompson, and S. Kalay, Development of continuous lateral and vertical track stiffness measurement techniques. Proceedings from railway engineering, London, 2002.

14. Grossoni, I., et al., The role of track stiffness and its spatial variability on long-term track quality deterioration. Proceedings of the Institution of Mechanical Engineers, Part F: Journal of Rail and Rapid Transit. 0(0).

15. Bruni, S., et al., Effects of train impacts on urban turnouts: Modelling and validation through measurements. Journal of Sound and Vibration, 2009. 324(3-5): p. 666-689.

16. Markine, V., M. Steenbergen, and I. Shevtsov, Combatting RCF on switch points by tuning elastic track properties. Wear, 2011. 271(1): p. 158-167.

17. Wan, C., V. Markine, and I. Shevtsov, Optimisation of the elastic track properties of turnout crossings. Proceedings of the Institution of Mechanical Engineers, Part F: Journal of Rail and Rapid Transit, 2016. 230(2): p. 360-373.

18. Grossoni, I., Y. Bezin, and S. Neves, Optimisation of support stiffness at railway crossings. Vehicle System Dynamics, 2018. 56(7): p. 1072-1096.

19. Le Pen, L., et al., Behaviour of under sleeper pads at switches and crossings-Field measurements. Proceedings of the Institution of Mechanical Engineers, Part F: Journal of Rail and Rapid Transit, 2018. 232(4): p. 1049-1063.

20. Auer, F., et al., Under sleeper pads in track-the UIC project. Eur Railw Rev, 2013. 19. 
21. DIN, Deutsche Norm 45673: Resilient elements used in railway tracks - Part 6: laboratory test procedures for under-sleeper pads of concrete sleepers. 2013, German Institute for Standardization: Berlin.

22. Abadi, T., et al., Measuring the area and number of ballast particle contacts at sleeper/ballast and ballast/subgrade interfaces. The International Journal of Railway Technology, 2015. 4(2): p. 45-72.

23. Bowness, D., et al., Monitoring the dynamic displacements of railway track. Proceedings of the Institution of Mechanical Engineers, Part F: Journal of Rail and Rapid Transit, 2007. 221(1): p. 13-22.

24. Lamas-Lopez, F., et al., Assessment of integration method for displacement determination using field accelerometer and geophone data Journal of Zhejiang University-SCIENCE A, 2017. 18(7): p. 553-566.

25. Le Pen, L., et al., The behaviour of railway level crossings: insights through field monitoring. Transportation Geotechnics, 2014. 1(4): p. 201-213.

26. Timoshenko, S. Method of analysis of statical and dynamical stresses in rail. in Proceedings of the Second International Congress for Applied Mechanics, Zurich Switzerland. 1926.

27. Priest, J.A., et al., The effect of enhanced curving forces on the behaviour of canted ballasted track. Proceedings of the Institution of Mechanical Engineers, Part F: Journal of rail and rapid transit, 2013. 227(3): p. 229-244.

28. Bezin, Y., et al., An investigation of sleeper voids using a flexible track model integrated with railway multi-body dynamics. Proceedings of the Institution of Mechanical Engineers, Part F: Journal of Rail and Rapid Transit, 2009. 223(6): p. 597-607.

29. Jorge, P.F.M., Modelling and enhancing track support through railway switches and crossings and transitions, in Department of Computing and Engineering. 2018, University of Huddersfield.

30. VI-Grade Engineering software and solutions. VI-Rail 18.0 manual users. 2017.

31. Bezin, Y., et al., The dynamic response of slab track constructions and their benefit with respect to conventional ballasted track. Vehicle System Dynamics, 2010. 48(Suppl.1): p. 175-193.

32. Piotrowski, J. and W. Kik, A simplified model of wheel/rail contact mechanics for nonHertzian problems and its application in rail vehicle dynamic simulations. Vehicle System Dynamics, 2008. 46(1-2): p. 27-49.

33. Shih, J.-Y., et al., Modelling options for ballast track dynamics, in 24th international congress on sound and vibration. 2017: London.

34. In2Track, D2.2: Enhanced S\&C whole system analysis, design and virtual validation. 2018. 